\title{
Dengue e falta de infraestrutura urbana na Amazônia brasileira: o caso de Altamira (PA)
}

\section{Dengue and the lack of urban infrastructure in the Brazilian Amazon: the case of Altamira (PA)}

Igor Cavallini Johansen - Bacharel em Sociologia e Ciência Política, Universidade Estadual de Campinas, 2011; mestrando do programa de pós-graduação em Demografia pela mesma universidade. E-mail: igor@nepo.unicamp.br

Roberto Luiz do Carmo - Pós-doutor em Demografia pela Brown University, 2010, é professor da Universidade Estadual de Campinas. E-mail: roberto@nepo.unicamp.br

Resumo

Procurou-se compreender neste estudo quais foram os principais fatores que contribuíram para a deflagração das epidemias de dengue no município de Altamira (Pará) nos anos de 2009 e 2010. Para tanto, buscou-se realizar a análise da relação dialética estabelecida entre população e ambiente. A dinâmica ambiental foi verificada a partir das condições de saneamento básico do município. Já a dinâmica populacional foi aferida a partir da observação da morbidade e mortalidade por dengue. Concluiu-se que a dengue consiste em um fenômeno complexo pela sua multicausalidade, ou seja, por possuir imbricações diversas e complexas entre seus fatores causais. Verificou-se, ainda, que as condições do saneamento básico ou infraestrutura urbana, mostraram ser não o único fator, mas provavelmente um dos mais importantes a serem considerados enquanto capazes de propiciar o desencadeamento de uma realidade epidêmica de dengue.

\section{Abstract}

We sought to understand in this study which were the main factors that contributed to the dengue epidemics in Altamira city (in Brazilian Para State) for the years 2009 and 2010. For this purpose, we attempted to perform the analysis of the dialectical relationship established between Population and Environment. On the one hand, the environmental dynamics were observed from the sanitation conditions in the municipality. On the other hand, the population dynamics were measured from the observation of morbidity and mortality due to dengue. It was concluded that dengue is a complex phenomenon for its multiple causes, in other words, by having imbrications among its diverse and complex causal factors. It was also shown that the sanitation conditions, or urban infrastructure, are not the only factor, but probably one of the most important things to consider as capable of providing the triggering of a dengue epidemic.

\section{Palavras-chave}

Dengue. Infraestrutura urbana. Altamira.

\section{Keywords}

Dengue. Urban infrastructure. Altamira. 


\section{INTRODUÇÃO ${ }^{1}$}

A dengue é um problema de saúde pública global e carece de esforços para ser compreendida e controlada. Estima-se que ocorram cinquenta milhões de infecções por dengue a cada ano em mais de 100 países. Aproximadamente dois bilhões e meio de pessoas vivem em territórios onde a dengue é endêmica, o que ocorre principalmente na Ásia, na África e na América do Sul (OMS, 2006; OMS, 2009; NATURE, 2007). Mas, diferentemente de várias doenças existentes nos países em desenvolvimento, a dengue atinge diversas classes sociais.

Gubler (1998) aponta que, de 1780 a 1940, o padrão da doença hoje associado à dengue foi caracterizado por epidemias relativamente pouco frequentes, mas muitas vezes de grandes dimensões. Foi no sudeste da Ásia e no Pacífico que teve início uma pandemia global de dengue. Em 1997, o vírus da doença e o mosquito Aedes aegypti, seu principal vetor, já detinham uma distribuição mundial, principalmente nos trópicos.

Nas quatro últimas décadas, a dengue foi reconhecida como a mais importante doença viral transmitida por mosquito, emergindo em países previamente considerados livres e ressurgindo naqueles onde a doença já havia sido controlada (SHEPARD et al., 2011).

As organizações sociais, políticas e econômicas transformam-se ao longo do tempo, assim como as formas de ocorrência e distribuição de doenças. A dengue não é uma exceção. Dentre os condicionantes que podem facilitar sua disseminação merecem registro: a intensificação das trocas de mercadorias e maior agilidade dos meios de transporte; os crescentes movimentos migratórios; a ampliação desordenada das cidades, cujo abastecimento irregular de água leva à necessidade de estoque doméstico, podendo vir a constituir novos criadouros do mosquito; e a inadequada coleta e destinação do lixo que, em conjunto com uma série de outros fatores, podem promover a proliferação do mosquito vetor dessa doença infecciosa (DONALISIO, 1999; TAUIL, 2001; HAYES et

\footnotetext{
Este artigo compreende as principais ideias da monografia apresentada ao Instituto de Filosofia e Ciências Humanas (IFCH) da Universidade Estadual de Campinas (UNICAMP), intitulada "Saneamento ambiental e dengue na Amazônia brasileira: o caso de Altamira (PA)", para a conclusão do curso de Ciências Sociais, com área de concentração nos Estudos de População. Os autores, orientando e orientador, agradecem o fomento concedido à presente pesquisa pelo Programa Institucional de Bolsas de Iniciação Científica (PIBIC/CNPq/UNICAMP) e também ao financiamento do National Institutes of Health (NIH/EUA) que, pelo processo número R01HD035811, possibilitou a aplicação do survey NEPO/UNICAMP na área urbana de Altamira, em janeiro de 2010, em parceria com as instituições norte-americanas de ensino superior Indiana University e Brown University. O conteúdo é somente de responsabilidade dos autores e não necessariamente representa as visões oficiais do NIH ou do CNPq.
} 
al., 2003; LINHARES; CELESTINO, 2006; BARRETO; TEIXEIRA, 2008; ANDRADE, 2009).

A dengue exige a constante renovação de conceitos e métodos para sua compreensão. Os surveys epidemiológicos foram aplicados na Tailândia (BENTHEM et al., 2005), em Bangladesh (ALI et al., 2003), em El Salvador (HAYES et al., 2003) e no Brasil (SIQUEIRA et al., 2004; LIMA et al., 2006) com o objetivo de compreender quais são os principais determinantes - como características entomológicas, sorotipos circulantes e atitudes e comportamentos da população - que culminam em maior ou menor risco de dengue.

Procurou-se compreender no presente estudo quais foram os principais fatores que contribuíram para a ocorrência das epidemias de dengue no município de Altamira (PA) nos anos de 2009 e 2010. Para tanto, buscou-se realizar a análise da relação dialética estabelecida entre população e ambiente. Por um lado, através da análise dos impactos da população no ambiente, observando o desenvolvimento do saneamento básico da cidade ao longo dos censos demográficos realizados pelo Instituto Brasileiro de Geografia e Estatística (IBGE), do Sistema Nacional de Informações sobre Saneamento (SNIS) e do survey realizado pelo NEPO/ UNICAMP, em janeiro de 2010, naquela cidade². Além disso, preconizou-se observar os impactos do ambiente na dinâmica demográfica através dos casos de dengue no município, que foram auferidos da base de dados eletrônica do Sistema de Informação de Agravos de Notificação (SINAN) e da Vigilância Epidemiológica de Altamira.

\section{DENGUE: UM PROBLEMA DE SAÚDE PÚBLICA GLOBAL}

\subsection{CARACTERÍSTICAS GERAIS DA DOENÇA}

A dengue é uma doença infecciosa, compreendendo um quadro virose aguda, típica de áreas urbanas, causada por um arbovírus que se distingue por quatro sorotipos distintos: DEN-1, DEN-2, DEN-3 e DEN-4. A infecção com um dos sorotipos provoca imunidade ao longo da vida para aquele sorotipo, mas não para os demais (GUBLER, 1998). A dengue pode ser assintomática, de modo que o indivíduo contaminado que não apresentou sintomas não sabe

2 Para esse survey, a amostra foi delineada a partir da seleção de dez setores censitários (IBGE) com a probabilidade proporcional ao tamanho do setor, e em seguida foi selecionada uma amostra de 50 unidades domésticas de cada um desses dez setores, totalizando, assim, 500 entrevistas. 
que teve dengue. $\mathrm{O}$ quadro sintomático, por sua vez, pode evoluir para febre de dengue (mais comum) ou dengue hemorrágica (forma mais severa, por vezes letal).

Constatam-se distintas características epidemiológicas de infecção por dengue na Ásia e no Brasil. Na Ásia, infecções sequenciais ocorrem em períodos muito mais curtos porque todos os quatro sorotipos de dengue estão ali em circulação concomitante, enquanto no Brasil geralmente há intervalos maiores entre epidemias de diferentes sorotipos. Nos países do Sudeste Asiático, as crianças são os mais usualmente atingidos pelos tipos mais perigosos da doença, a febre hemorrágica de dengue e a síndrome do choque de dengue, já no Brasil esses quadros afetam mais frequentemente a população adulta (CORDEIRO et al., 2007).

A dengue se distribui ao longo de uma faixa abaixo e acima da linha do Equador, latitude $35^{\circ} \mathrm{N}$ e $35^{\circ} \mathrm{S}$ (Figura 1). Tem-se que até a metade da década de 1990, o Sudeste Asiático compreendia a região do mundo mais atingida por dengue. A partir desse momento, os países da América Central e da América do Sul passaram a se destacar nesse cenário, contribuindo com muito mais da metade dos casos notificados no mundo. O caso do Brasil é notório: apenas no ano de 2008, o país registrou mais de 700 mil casos da doença. Assim, a Figura 3 evidencia a importância da dengue enquanto uma das doenças virais transmitidas por mosquito que mais rapidamente se espalhou pelo mundo. Em trinta anos, a incidência cresceu trinta vezes, com a paralela expansão geográfica da doença a novos países (OMS, 2009).

Os sintomas da "dengue clássica", na maioria dos casos, são de caráter benigno (incapazes de levar à morte), como febre abrupta e intermitente, dor de cabeça, dor nas articulações, dor muscular (localizada ou não), dor retroorbital, náusea e vômitos. Apesar de possuir um índice de letalidade baixo, a dengue clássica, por ser a mais comum, produz sérios transtornos individuais e sociais, que ganham uma dimensão maior a cada nova epidemia. As formas severas, a Febre Hemorrágica de Dengue (FHD) e a Síndrome do Choque de Dengue (SCD), compreendem um quadro febril agudo, que se inicia como a dengue clássica, mas evolui com a queda do estado geral, taquicardia, queda da pressão arterial, diminuição da circulação sanguínea nos tecidos periféricos e manifestações hemorrágicas. Os sinais externos que indicam o agravamento do quadro de dengue clássica para a hemorrágica incluem o aparecimento de 
manchas vermelhas na pele, sangramentos (nariz, gengivas), dor intensa e contínua no abdômen e vômitos persistentes (BRASIL, 2011). Infecções sequenciais por distintos sorotipos favorecem a expressão hemorrágica da dengue. Essa forma severa abarca quadros graves da infecção pelo vírus, associados à alta letalidade (dez por cento, especialmente em crianças) (DONALISIO, 1999). Mais de 500 mil pessoas contraem dengue hemorrágica por ano no mundo, dentre as quais cerca de 20 mil morrem (NATURE, 2007).

Figura 1: Países/áreas de risco de transmissão de dengue, 2008.

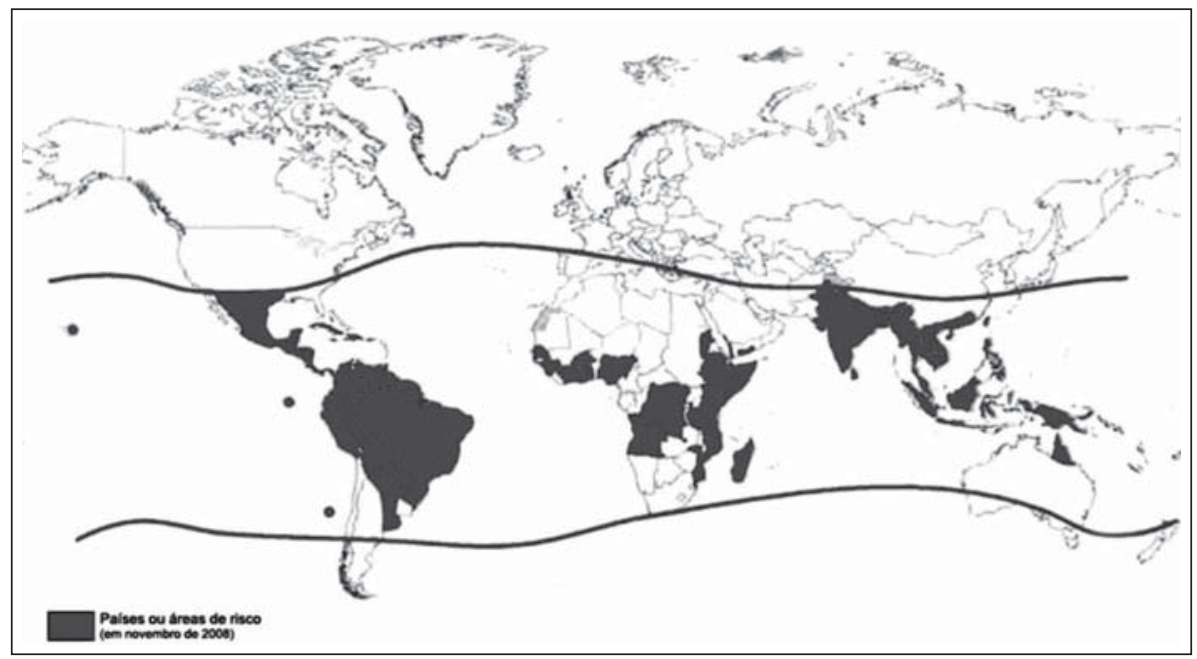

Fonte: Organização Mundial da Saúde (OMS) (2009, p. 3).

Nota: As linhas vermelhas indicam os limites geográficos potenciais em relação aos hemisférios Norte e Sul de sobrevivência do Aedes aegypti, o principal mosquito vetor do vírus da dengue.

\section{O mosquito transmissor}

A dengue é transmitida aos seres humanos por intermédio dos mosquitos Aedes (aegypti, mais comum, ou albopictus). Nas Américas, o Aedes aegypti é o único transmissor desse vírus com importância epidemiológica (BARRETO; TEIXEIRA, 2008). O ciclo da doença compreende dois estágios principais: 1) fêmeas adultas ${ }^{3}$ dos mosquitos Aedes adquirem o vírus picando um humano infectado e 2) o vírus é transmitido a outras pessoas via picadas dos mosquitos infectados (GUBLER, 1998; DONALISIO, 1999; TAUIL, 2001; ALI et al., 2003; OMS, 2009).

O mosquito Ae. aegypti é altamente adaptado ao ambiente doméstico e

3 Apenas as fêmeas adultas são hematófagas porque necessitam de sangue para obter proteínas e colocar seus ovos. Os machos, por sua vez, obtêm nutrientes apenas a partir da seiva vegetal (NATURE, 2007). 
muito comum em regiões tropicais, preferindo colocar seus ovos em recipientes com água comumente encontrados dentro e ao redor de casas, como, por exemplo, vasos de plantas, pneus velhos, lixo em geral, cisternas e, até mesmo fossas sépticas, produzindo um grande número de mosquitos adultos em grande proximidade com as habitações humanas. O Aedes aegyptié bastante parecido com o pernilongo comum, o Culex quinquefasciatus, entretanto o Aedes é mais escuro e possui pequenas marcas brancas pelo corpo e pelas patas (Figura 2), tendo como costume atacar as pessoas durante o dia (GUBLER, 1998). Segundo o Ministério da Saúde (2006), já foi detectado que os ovos desse mosquito sobrevivem até dois anos sem contato com a água. Assim que dispõem de condições favoráveis, eles eclodem e dão continuidade ao ciclo de vida.

Figura 2: Fases de desenvolvimento do Aedes aegypti.

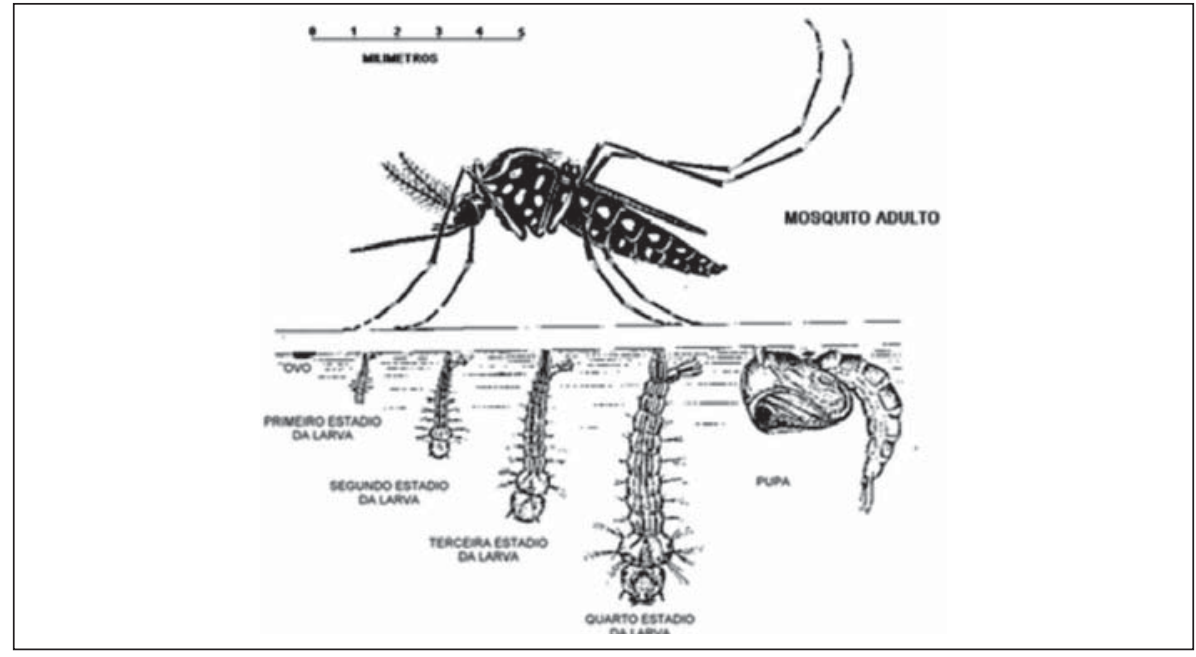

Fonte: Prefeitura Universitária UNICAMP.

\subsection{A DENGUE NAS AMÉRICAS}

A campanha continental americana de erradicação do Ae. aegypti foi iniciada oficialmente em 1947, alcançando relativo sucesso no decorrer da década de 1950, em consonância com o controle desse vetor em 21 países e várias pequenas ilhas do Caribe (SANTOS; AUGUSTO, 2005). Dessa forma, nas décadas de 1950, 1960 e grande parte de 1970, as epidemias de dengue eram raras no continente americano, pois seu principal vetor nessa região, o Ae. aegypti, havia sido aparentemente erradicado da maior porção das Américas Central e do Sul. 
Os fatores responsáveis pela ressurgência da dengue epidêmica e emergência da febre hemorrágica de dengue, enquanto um alarmante problema de saúde pública na região desde 1981, são complexos e não totalmente compreendidos. Sabe-se, entretanto, que um dos principais elementos que possivelmente contribuíram para essa reaparição foi o fato de que os programas de erradicação não tiveram continuidade ao longo da década de 1970 e o mosquito transmissor começou a reinfestar os países nos quais já havia sido controlado. Assim, na década de 1980, o continente americano vivenciou a introdução de novos sorotipos de dengue e, na década de 1990, o Ae. aegypti já havia quase reconquistado todos os espaços dos quais havia praticamente desaparecido (GUBLER, 1998; SANTOS; AUGUSTO, 2005; BRAGA; VALLE, 2007).

Gubler (1998) indica que no passado os programas detinham uma estrutura organizacional vertical e paramilitar, com um grande contingente de pessoas e alto orçamento. Nos anos recentes, segundo ele, a ênfase tem sido dada às abordagens baseadas na comunidade para a redução larval, de modo a promover a sustentabilidade do programa. Nessa mesma direção, acena Abrahão (2005), sobre a necessidade de se suplantar o modelo químico-dependente (utilização de agentes químicos no controle de vetor), ao propor uma abordagem ecossistêmica para o controle da doença, de forma mais ampla, que assente suas bases na ação ativa e contínua das redes sociais, operando no sentido de beneficiar a coletividade e a preservação ambiental. "Ao modelo químico-paternalista apresenta-se alternativa ecológica e pró-ativa" (GULBER, 1998, p. 138).

Talvez a principal dificuldade para a compreensão da real dimensão da doença atualmente seja a subnotificação (OMS, 2009; SHEPARD et al., 2011), pois: a) um dos quadros da dengue é assintomático (sobre esses casos há apenas estimativas); b) tem-se o quadro sintomático de "dengue clássica", que é confundido com outras enfermidades como gripe ou viroses transitórias, de modo que as pessoas afetadas não procuram o sistema de saúde; e c) a má preparação de alguns profissionais da área da saúde para diagnosticar a doença rapidamente e levar a cabo a notificação e confirmação do caso.

Além disso, uma das questões mais complexas para o controle da dengue consiste no fato de que, apesar do significante aumento da compreensão da doença pela população, em especial do ciclo reprodutivo do mosquito vetor, as ações não se modificam suficientemente para impactar o potencial de transmissão da dengue (THE ROCKEFELLER FOUNDATION, 1988; RANGEL-S, 2008; FERREIRA et al., 2009).

Vacinas contra a dengue já estão em desenvolvimento, algumas até mesmo em fase de testes (OMS, 2009; COSTA, 2011), de modo que alguns estudiosos 
têm se dedicado a analisar seu potencial econômico (relação custo-benefício), com o intuito de auxiliar os formuladores de políticas públicas no processo de tomada de decisão (BEATTTY et al., 2011; LEE et al., 2011). Outros pesquisadores, ainda, verificam o impacto econômico da dengue. Assim, estima-se que o custo da doença nas Américas, de 2000 a 2007, tenha sido de 2,1 bilhões de dólares por ano (cotação em dólares americanos de 2010). Como nessa cifra não se incluem alguns componentes, como controle de vetores, as consequências econômicas da dengue ainda podem estar aí subestimadas. É importante lembrar que o Brasil é o país com o maior número absoluto de casos de dengue das Américas e, também, onde os custos decorrentes da doença são os mais elevados (SHEPARD et al., 2011).

\subsection{A DENGUE NO BRASIL}

Santos e Augusto (2005) analisam o Programa de Erradicação do Aedes aegypti (PEAa) implantado no Brasil em 1996. A análise desse programa favorece a compreensão dos modelos oficiais historicamente adotados para o controle de endemias vetoriais, em particular a dengue. A apresentação do PEAa pelo Ministério da Saúde soou como uma revolução no modelo de abordar a dengue, manejando um discurso integrador que atuava sobre diversos "componentes": saneamento, educação e uma meta ambiciosa de se erradicar o mosquito transmissor até o ano 2000.

Todavia, as metas iniciais do PEAa, que previam a partir de 1998 uma queda acentuada no número de municípios infestados pelo vetor, não foram alcançadas. Contrariamente, conforme dados do próprio Ministério da Saúde (BRASIL, 2011), em 1995, 1.753 municípios estavam infestados pelo Ae. aegypti e em 2010 esse número aumentou para 4.007. Esse fracasso (Figura 3) pode ser resultado do fato de que, "[...] na prática, o primeiro (saneamento) e o segundo grupo (educação) não foram implementados. O terceiro foi executado quase exclusivamente pela adoção do modelo químico de controle do vetor" (SANTOS; AUGUSTO, 2005, p. 120).

Analisa-se, ainda, que, desde 2001, por conta da resistência (já esperada) do mosquito aos inseticidas, os produtos químicos passaram a ser criticados e surgiu proposta de sua substituição por outros meios como, por exemplo, larvicidas biológicos, que são produtos de origem natural que não contaminam o ambiente, não são venenosos, não são tóxicos para o ser humano quando aplicados e não atacam plantas nem animais vertebrados. Para Santos e Augusto (2005), o erro central da ação esteve presente na ideia que norteou o PEAa, ou seja, a crença 
na erradicação com o objetivo de manter permanentemente todos os municípios do país sem a presença do mosquito e, desse modo, extinguir a possibilidade de transmissão da dengue.

Os posteriores ajustes realizados no PEAa levaram à falsa ideia de inovação. Quando se percebeu que as estratégias adotadas não estavam correspondendo aos objetivos programados, em 1998 esse modelo foi revisado por intermédio do "Ajuste Operacional do PEAa". Outro ajuste foi o "Plano de Intensificação das Ações de Controle do Dengue (PIACD) ${ }^{4}$ ", caracterizado pela reformulação do Programa de Erradicação do Ae. aegypti, diante da constatação da impossibilidade de se erradicar o mosquito vetor da dengue.

Figura 3: Municípios infestados por Aedes aegypti no Brasil - 1995/2010.

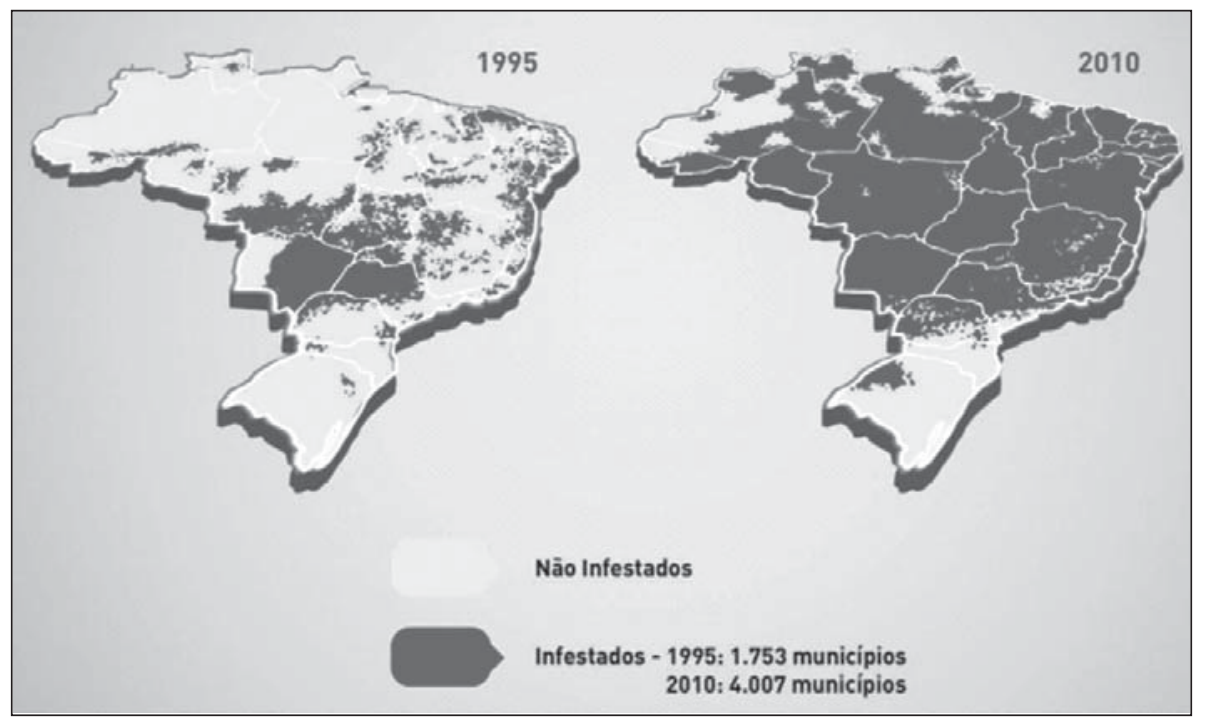

Fonte: Brasil, 2011.

Entretanto, Santos e Augusto (2005) observam que o "novo" modelo que caracterizou o PIACD manteve a característica verticalizada quanto a sua concepção. Além disso, o poder público teria continuado a se desobrigar de agir de forma pró-ativa em relação aos problemas que estariam diretamente relacionados com a veiculação do vetor da dengue, como, por exemplo, o saneamento ambiental:

4 Esse plano incorporou maior preocupação aos aspectos epidemiológicos da introdução do sorotipo 03 do vírus, a disponibilidade de criadouros artificiais e a enorme facilidade de dispersão passiva do vetor pela maior disponibilidade, frequência e rapidez dos meios de transporte. 
O poder público não assume concretamente perante a coletividade suas responsabilidades relacionadas com os problemas de infra-estrutura [sic] urbana para um ambiente saudável. A ausência de um enfoque sistêmico que apresente o dengue em suas diversas dimensões (biológica, ecológica, mudanças climáticas globais, modelo de desenvolvimento econômico com exclusão social) limita a participação social ao aspecto individual pouco transformador (SANTOS; AUGUSTO, 2005, p. 124).

Todavia, é importante matizar a afirmação de que o poder público se desobrigou a investir em ações relativas ao provimento dos serviços básicos de saneamento ambiental. $\mathrm{Na}$ realidade, houve avanços em termos de investimentos em infraestrutura no Brasil. Todavia, esses investimentos não foram realizados pari passu com o ritmo da expansão urbana no país. Diante dessa situação, emergiram ou se intensificaram problemas como a dengue, enquanto questão de saúde que afeta diretamente a população. Além disso, como se argumenta ao longo deste trabalho, as epidemias de dengue não podem ser creditadas apenas aos problemas de infraestrutura deflagrados nos ambientes urbanos, apesar de ser esse um importante fator para a ocorrência de uma epidemia. Neste sentido, a Organização Pan-Americana de Saúde (OPAS) publicou, em 2001, um documento em que vincula a problemática da dengue à falta de saneamento nos domicílios, associando a existência de criadouros também a comportamentos individuais e coletivos e reforçando a proposta do controle integrado.

\subsubsection{Imbricações com o processo brasileiro de urbanização}

Faria (1991) analisa o processo brasileiro de urbanização intensificado, principalmente, a partir de 1945. O autor salienta que

[...] entre 1945 e 1980 a sociedade brasileira conheceu taxas bastante elevadas de crescimento econômico e sofreu profundas transformações estruturais. Ficou para trás a sociedade predominantemente rural, cujo dinamismo fundava-se na exportação de produtos primários de base agrícola, e emergiu uma complexa e intrigante sociedade urbano-industrial (FARIA, 1991, p. 102).

Nesse contexto, segundo ele, foram expandidos os serviços de saúde, principalmente os serviços de medicina curativa, a cobertura previdenciária e a educação pública de primeiro e segundo graus. Entretanto, os "serviços de consumo coletivo", como infraestrutura urbana, não tiveram o mesmo grau de desenvolvimento. Tem-se como um dos principais fatores desse "retardamento" o alto custo desse tipo de investimento: 
Nos serviços de consumo coletivo em que o investimento exigido é mais vultuoso por unidade de serviço ou que requerem somas agregadas mais vultuosas, como na habitação, no transporte coletivo de massa e no saneamento básico, os avanços - diferentes nos diferentes setores e em diferentes regiões urbanas do país - foram ainda menos significativos (FARIA, 1991, p. 108).

Assim, a tônica do processo de expansão urbana deflagrado no país foi o não acompanhamento das políticas públicas de saneamento ambiental (FARIA, 1991; SANTOS; AUGUSTO, 2005; BRAGA; VALLE, 2007). Concomitantemente a esse processo, tem-se que a dengue passou a ser um problema de saúde pública no Brasil a partir dos anos 1980:

A história do dengue ${ }^{5}$ como relevante problema de saúde pública no Brasil é recente. Até os anos 80, não estavam confirmados surtos importantes de doença. O Ae. aegypti foi introduzido durante o período colonial, provavelmente na época do tráfico de escravos. Por ser o vetor da febre amarela urbana, foi combatido e considerado erradicado em 1955 (SANTOS; AUGUSTO, 2005, p. 115).

Em 1981, em Boa Vista (RR), ocorreu o primeiro registro de casos clínicos de dengue em forma epidêmica. Estimou-se que nesse período tenha ocorrido uma taxa de incidência de três mil casos para cada cem mil habitantes (SANTOS; AUGUSTO, 2005).

Argumenta-se que as características da urbanização brasileira ao longo da segunda metade do século XX estão relacionadas ao processo de reemergência do Ae. aegytpi e à rápida expansão das epidemias de dengue pelo país:

Mudanças demográficas nos centros urbanos resultaram em significativos contingentes populacionais morando em sub-habitações, com sistemas precários de abastecimento de água e saneamento ambiental muitas vezes inexistente. Comportamentos ambientalmente desfavoráveis, com oferta de inúmeros criadouros em ambientes domésticos, destinação inadequada de lixo e resíduos de uma forma geral, constituem-se a base para a expansão do habitat urbano do mosquito vetor [...] (ABRAHÃO, 2005, p. 142).

Donalisio (1999) também faz referência à interrelação entre falta de saneamento ambiental e formas de organizar a vida em sociedade com a transmissão facilitada da dengue nas áreas de maiores concentrações populacionais:

\footnotetext{
Apenas a título de esclarecimento, segundo o Dicionário Aurélio, o substantivo "dengue" é masculino: o dengue hemorrágico. Para o Dicionário Houaiss, é feminino: a dengue hemorrágica. O Vocabulário Ortográfico da Academia Brasileira de Letras (ABL) considera "dengue" um substantivo de dois gêneros: "o dengue" ou "a dengue".
} 
A transmissão facilitada nas áreas metropolitanas e de altas concentrações populacionais é também decorrência das formas de organizar a vida na sociedade: a ocupação diferenciada dos espaços, a limpeza pública, os resíduos urbanos, os sistemas de drenagem e escoamento das águas servidas, o saneamento, as periferias urbanas com seus consumos e carências, além dos variados e conjunturais deslocamentos da população (DONALISIO, 1999, p. 77).

No mesmo sentido, Carmo (2009) pondera que um dos impactos do processo de urbanização na água disponível consiste na reemergência da epidemia de dengue, relacionada à falta de serviços de infraestrutura básica, como água canalizada, esgoto e coleta de lixo. Desse modo, indica-se que a dengue encontra condições favoráveis de procriação diante, do processo de urbanização característico do Brasil: "A falta de abastecimento regular de água e coleta de lixo público que acompanhou o processo de urbanização do Brasil criou condições para a proliferação de criadouros potenciais para o Aedes aegypti”' (CARMO, 2009, p. 11, tradução livre).

\subsubsection{A importância da mobilidade populacional}

Já se verificou que no Brasil a variação genética do mosquito é independente da distância geográfica separando cidades, o que sustenta a hipótese de que os Ae. aegypti infectados não são passíveis de espalhar o vírus da dengue por longas distâncias, independentemente do período do ano (COSTA-RIBEIRO et al., 2007). Essa conclusão pode levar à assertiva de que neste país, se a questão da rápida dispersão do vírus da dengue não está relacionada à mobilidade do mosquito por rotas entre cidades e regiões, os mais prováveis propulsores de tal circulação são os fluxos de seres humanos contaminados, o que evidencia a importância desse componente da dinâmica demográfica.

A correlação entre mobilidade populacional e dengue já foi observada no estudo de Andrade (2007) sobre a doença nos municípios do estado de São Paulo, entre 1995 e 2005, no qual se verificou a existência de um eixo entre os municípios de São José do Rio Preto e Miguelópolis, no norte do estado, onde era constante a reincidência de casos de dengue ao longo do período estudado. Esse eixo é interligado por uma importante rodovia do estado: a SP-425. Não obstante, a região é palco de um considerável movimento pendular, isto é, a mobilidade de pessoas que residem em "cidades dormitório", mas se deslocam diariamente para estudar ou trabalhar em municípios vizinhos, o que, segundo o autor, potencializaria a distribuição do vírus da dengue entre as cidades que tangenciam a rodovia. 


\subsubsection{O Programa Nacional de Controle da Dengue}

O mais recente plano de controle da dengue no Brasil, que pauta até hoje as ações e políticas públicas no controle da doença, foi implantado em 2002, sendo denominado Programa Nacional de Controle da Dengue (PNCD). Nesse, a característica de um programa "permanente" foi enfatizada, distinguindo-o das versões anteriores consideradas agora pelo Ministério da Saúde como "campanhistas". Além disso, foram incorporados elementos como a mobilização social e a participação comunitária, indispensáveis para responder de forma adequada a um vetor altamente domiciliado (PNCD, 2002; SANTOS; AUGUSTO, 2005).

Todavia, um dos problemas centrais verificados na coordenação das ações contra a dengue no Brasil compreende seu o modelo de comunicação, caracterizado pela descontinuidade, com ênfase para situações epidêmicas e mais profundamente difundido apenas nos meses de maior pluviosidade (quando é maior o risco de contrair a dengue). Além disso, permanece a terminologia pertinente à guerra, metáfora familiar e tão antiga quanto a Saúde Pública na sua luta ou combate para exterminar os inimigos biológicos (RANGEL, 2008).

A ineficácia do modelo de comunicação pode, por vezes, gerar a descrença de que um "mosquitinho" possa causar tamanho problema (LEFÈVRE et al., 2004). Verifica-se, todavia, que as taxas de incidência e número de municípios com alta densidade de mosquitos Ae. aegypti cresceram vertiginosamente no Brasil nos últimos 30 anos (Figura 4).

Figura 4: Taxa de incidência de dengue* e número de municípios com alta densidade de mosquitos Aedes aegypti, no Brasil - 1985-2010.

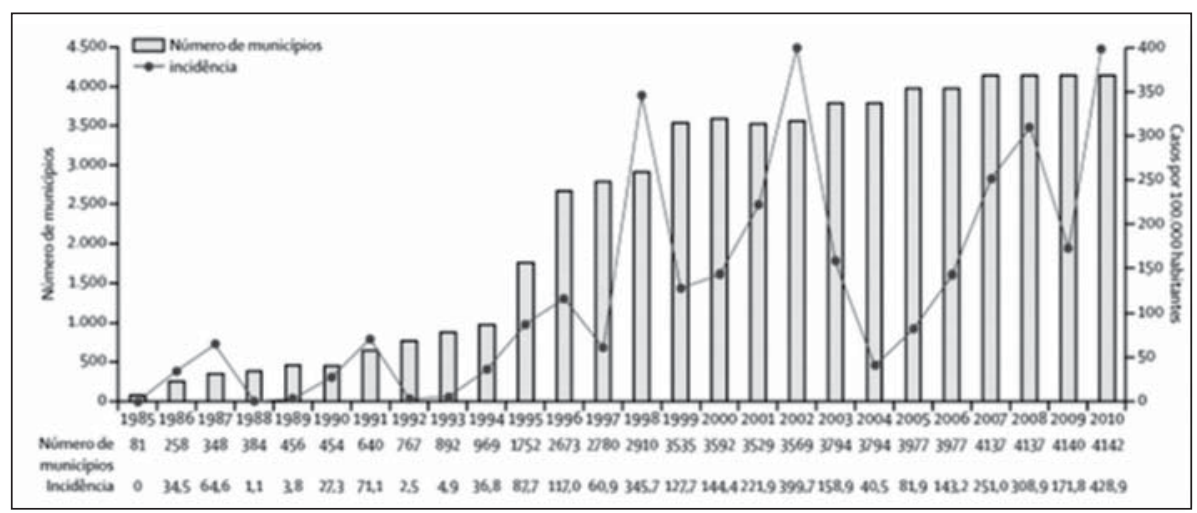

Fonte: Barreto et al. (2011, p. 55).

Nota: * A taxa de incidência de dengue compreende o número de casos confirmados de dengue (clássico e febre hemorrágica de dengue), por 100 mil habitantes, em determinado espaço geográfico e no ano considerado. Assim, Taxa de Incidência de dengue $=$ (Número de casos de dengue confirmados em residentes/ População Total Residente) x 100.000 (RIPSA, 2011). 
Nesse contexto de expansão da dengue, os municípios da Amazônia brasileira figuram entre os mais recentemente infestados pelo mosquito Aedes aegypti e, consequentemente, pela dengue. Isso ocorre, em certa medida, pelo acelerado processo de urbanização, cuja característica mais evidente é o não acompanhamento das políticas públicas de saneamento ambiental. O caso de Altamira é emblemático.

\section{DENGUE NA AMAZÔNIA BRASILEIRA: O CASO DE ALTAMIRA, NO PARÁ}

\subsection{CONTEXTO HISTÓRICO: O PROCESSO DE URBANIZAÇÃO NA AMAZÔNIA}

De acordo com Ribeiro (1993), o processo de urbanização da Amazônia entre as décadas de 1960 e 1990 está intimamente ligado à apropriação capitalista da fronteira, que foi intensificada pelas ações oficiais como o Programa de Polos Agropecuários e Agrominerais (Polamazônia), o Programa Grande Carajás (PGC) e, principalmente, a implantação dos grandes projetos incentivados pela Superintendência de Desenvolvimento da Amazônia (SUDAM) que, interligados a outros acontecimentos importantes, como a criação da Zona Franca de Manaus, em 1967, e a concretização de uma grande infraestrutura de grandes eixos, baseada no sistema rodoviário, garantiram a viabilização dos programas propostos.

O mesmo autor assinala que, para uma concepção de rede urbana na fronteira, é preciso levar em consideração dois elementos:

A nova divisão territorial do trabalho, que culmina em novas funcionalidades urbanas, ou através da criação de novos centros ou pelo rejuvenescimento de velhas cidades e na estagnação de outras, gerando uma alteração na hierarquia urbana, como, por exemplo, a quebra do papel hegemônico de Belém; a criação das "company towns" e, ainda, a ascendência de Manaus como centro industrial - metrópole regional.

Novos padrões de interações espaciais são verificados através de uma maior complexidade dos fluxos, que se apresentam mais ativos, diversificados e multidirecionados.

Assim, o processo de inserção da Amazônia Legal na estrutura nacional e mundial se consolida de modo desigual em termos espaciais, intensificando a diferenciação urbana (a partir da complexidade funcional das cidades, com uma divisão territorial do trabalho mais intensa), criando novas formas - ou 
readaptando as antigas - para novas funcionalidades e, ao mesmo tempo, marginalizando outras.

A urbanização na Amazônia ocorre em ritmo mais acelerado que o do país como um todo, ainda que o grau de urbanização regional seja inferior ao do Brasil (HOGAN et al., 2008). Para se ter uma ideia, em 1970 a população da Amazônia Legal era composta por 63\% de população rural e apenas 37\% urbana. Em 1991 essa razão se inverte, e a população passa a viver predominantemente nas cidades (56\%) e, já em 2000, 69\% reside em áreas definidas como urbanas e 31\% em áreas rurais (IBGE, 1970; 1991; 2000). Desse modo, o crescimento demográfico na Amazônia concentrou-se principalmente nos núcleos urbanos, a ponto de a região ser denominada de 'floresta urbanizada' (BECKER, 2007). A rápida urbanização gerou problemas de crescimento urbano desorganizado, com favelização e carência de serviços e equipamentos para atender a população.

\subsection{CARACTERIZAÇÃO SOCIOESPACIAL DA ÁREA DE ESTUDOS}

O município de Altamira está localizado no oeste do estado do Pará (Figura 5), na microrregião de Altamira, distante $512 \mathrm{~km}$ em linha reta da capital do estado, Belém, ou $720 \mathrm{~km}$ por via rodoviária na rota de Tucuruí (PREFEITURA MUNICIPAL DE ALTAMIRA, 2003). Lindeiro a dois dos eixos de transportes, o território municipal de Altamira recebe influência da rodovia Transamazônica, em sua porção norte e a oeste da rodovia BR-163. De acordo com os dados do Instituto Brasileiro de Geografia e Estatística (IBGE), esse município possui área de aproximadamente 160 mil km² , configurando-se como o maior do país em extensão territorial. Além disso, está inserido em um dos mais ricos biomas brasileiros em biodiversidade - a Amazônia.

A temperatura média anual no município é de $26^{\circ} \mathrm{C}$, com máxima de $31^{\circ} \mathrm{C}$ e mínima de $21,9^{\circ} \mathrm{C}$. Com alto volume de precipitações mensais, a umidade relativa média mensal de Altamira é alta, 84\%. O período de menor umidade relativa, com significativa diminuição das chuvas, abarca os meses de julho a novembro de cada ano. Assim, a média de precipitações é de 55,5 mm de julho a novembro, mas alcança a média de 287,1 $\mathrm{mm}$ de dezembro a junho (PREFEITURA MUNICIPAL DE ALTAMIRA, 2003). Essa alta pluviosidade pode ser um importante componente para a proliferação de vetores alados, como os mosquitos, principalmente quando combinada com temperaturas elevadas (CÂMARA et al., 2009). 
Acerca da atividade econômica, a agricultura - principalmente arroz, cacau, feijão, milho e pimenta-do-reino -, a extração da borracha e da castanhado-pará, além da pecuária são os principais motores da economia do município. Desde o período da borracha (fins do século XIX até meados do século XX) a rede urbana da região do Xingu estrutura-se a partir de Altamira (PREFEITURA MUNICIPAL DE ALTAMIRA, 2003).

Figura 5: Localização do município de Altamira, PA.

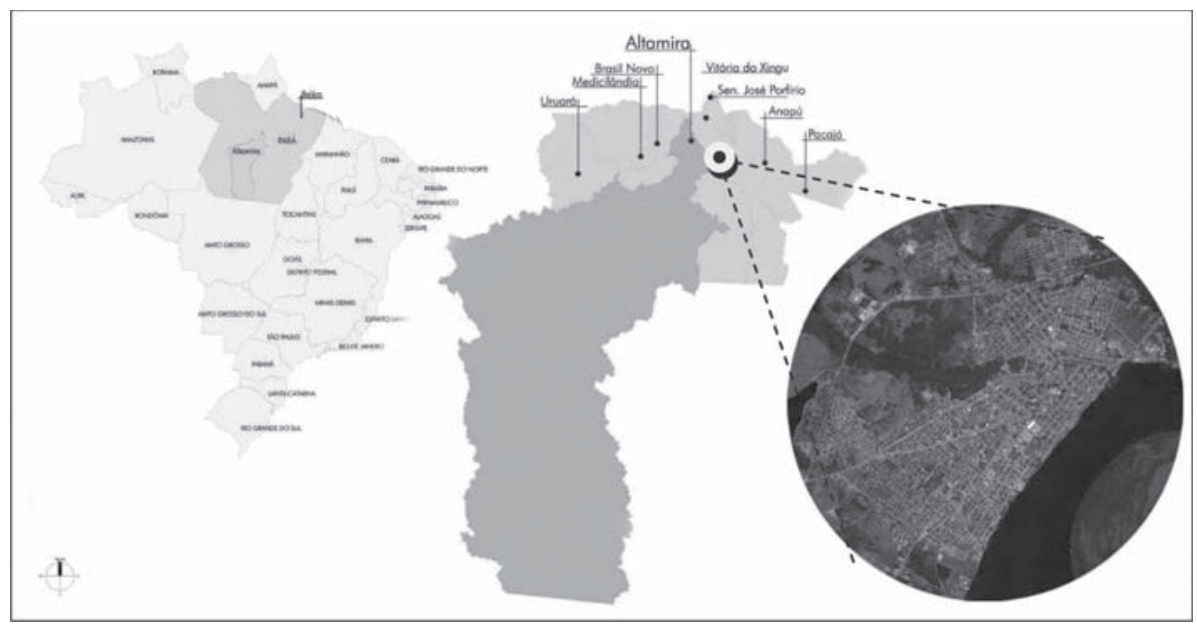

Fontes: Prefeitura Municipal de Altamira, 2003 (com modificações).

Google Earth, 2011.

A municipalidade possuía, em 1970, uma população total de 15.345 habitantes (62\%) residindo na zona rural. Entre 1970 e 1980, a população do município triplicou e a proporção rural-urbano começou a ser modificada, com a ocupação da área urbana de Altamira. Em 1980, predominou a ocupação urbana, seguindo o fenômeno da urbanização verificado no Brasil e na Amazônia durante esse período. Em 2010, segundo dados do Censo Demográfico do IBGE, a população total de Altamira era de 99.075 habitantes, com grau de urbanização ${ }^{6}$ próximo a $85 \%$ (Tabela 1$)$.

6 O grau de urbanização denota o porcentual da população urbana em relação à população total. É calculado, geralmente, a partir de dados censitários. Assim, grau de urbanização = (população urbana/ população total) x 100. 
Tabela 1: Volume e percentual populacional conforme situação de residência, Altamira - 1970-2010.

\begin{tabular}{l|c|c|c|c|c|c|c|c|c|c}
\hline \multirow{2}{*}{ Zona } & \multicolumn{10}{c}{ Ano } \\
\cline { 2 - 12 } & $\mathbf{1 9 7 0}$ & $\mathbf{0}$ & $\mathbf{1 9 8 0}$ & $\mathbf{0}$ & $\mathbf{1 9 9 1}$ & $\mathbf{0}$ & $\mathbf{2 0 0 0}$ & $\mathbf{\%}$ & $\mathbf{2 0 1 0}$ & $\mathbf{\%}$ \\
\hline Urbana & 5.905 & 38,5 & 26.905 & 57,9 & 50.145 & 69,3 & 62.285 & 80,4 & 84.092 & $\mathbf{8 4 , 9}$ \\
Rural & 9.440 & 61,5 & 19.591 & 42,1 & 22.263 & 30,7 & 15.154 & 19,6 & 14.983 & 15,1 \\
TOTAL & 15.345 & 100,0 & 46.496 & 100,0 & 72.408 & 100,0 & 77.439 & 100,0 & 99.075 & 100,0 \\
\hline
\end{tabular}

Fonte: IBGE - Censos Demográficos 1970, 1980, 1991, 2000 e 2010.

É importante evidenciar, entretanto, que o volume de pessoas residindo na área rural do município aumentou entre 1970 e 2010. Essa população vivendo no meio rural em 2010 (cerca 15 mil pessoas) representava quase três vezes a população vivendo na área urbana do município em 1970 (quase 6 mil pessoas). No que diz respeito à taxa de crescimento populacional de Altamira, nos últimos quarenta anos percebe-se que a tendência é de redução do crescimento, comparando-se o período inicial (1970/1980) e final (2000/2010) da sequência histórica (Tabela 2). Entre 1970 e 1980 a população do município cresceu cerca de 12\% ao ano. Entre 1980 e 1991 esse crescimento caiu para 4\% e, entre 1991 e 2000, houve queda ainda maior, para 0,7\% ao ano. Contudo, entre 2000 e 2010, a população do município cresceu cerca de 2,5\% ao ano. A retomada do crescimento no período recente pode estar relacionada à expectativa em relação aos grandes investimentos na região, principalmente em decorrência da instalação da Usina Hidrelétrica de Belo Monte, com a abertura de novos postos de trabalho. Observa-se na Tabela 2 que o crescimento populacional de Altamira contou com uma variação maior entre os períodos de 1970-1980 a 2000-2010 $(-9,2 \%)$, comparando-se com o estado do Pará como um todo $(-2,6 \%)$ e com o Brasil (-1,3). 
Tabela 2: Taxa de crescimento geométrico anual da população residente no município, em comparação com o estado e o país - 1970-2010.

\begin{tabular}{|c|c|c|c|c|c|c|}
\hline \multirow[b]{2}{*}{ Local } & \multirow[b]{2}{*}{ Zona } & \multicolumn{4}{|c|}{ Períodos } & \multirow{2}{*}{$\begin{array}{l}\text { Variação } \\
{[\mathrm{A}]-[\mathrm{D}]}\end{array}$} \\
\hline & & $\begin{array}{c}1970 / 1980 \\
{[\mathrm{~A}]}\end{array}$ & $\begin{array}{c}1980 / 1991 \\
{[\mathrm{~B}]}\end{array}$ & $\begin{array}{c}1991 / 2000 \\
{[C]}\end{array}$ & $\begin{array}{c}2000 / 2010 \\
{[D]}\end{array}$ & \\
\hline \multirow{3}{*}{ Altamira } & Urbana & 16,4 & 5,8 & 2,4 & 3,0 & \\
\hline & Rural & 7,6 & 1,2 & $-4,2$ & $-0,1$ & \\
\hline & TOTAL & 11,7 & 4,1 & 0,7 & 2,5 & $-9,2$ \\
\hline \multirow{3}{*}{ Pará } & Urbana & 5,0 & 4,1 & 5,3 & 2,3 & \\
\hline & Rural & 4,2 & 2,8 & $-1,4$ & 1,4 & \\
\hline & TOTAL & 4,6 & 3,5 & 2,5 & 2,0 & $-2,6$ \\
\hline \multirow{3}{*}{ Brasil } & Urbana & 4,4 & 3,0 & 2,4 & 1,6 & \\
\hline & Rural & $-0,6$ & $-0,7$ & $-1,3$ & $-0,7$ & \\
\hline & TOTAL & 2,5 & 1,9 & 1,6 & 1,2 & $-1,3$ \\
\hline
\end{tabular}

Fonte: IBGE - Censos Demográficos 1970, 1980, 1991, 2000 e 2010.

\subsection{SANEAMENTO AMBIENTAL EM ALTAMIRA}

Conforme os dados apresentados na Tabela 3, com informações sobre saneamento ambiental em Altamira, entre os anos censitários de 1991 e 2000, o IBGE aponta que, para o ano 2000, aproximadamente $19,7 \%$ da população do município dispunha de abastecimento de água via rede geral, com 74,9\% utilizando-se de poço ou nascente (na propriedade) e 5,4\% com outra forma de suprimento de água. Tomando por base os dados de 1991, verifica-se a redução da proporção de habitantes do município que se utilizam de rede geral e o aumento daqueles que lançam mão de poços ou nascentes na propriedade para obterem água. No que diz respeito às instalações sanitárias, a utilização de fossas sépticas e rudimentares (estas últimas em maior proporção) continuam a ser a regra geral no município. Já na questão dos resíduos sólidos coletados, observa-se um aumento proporcional expressivo do lixo coletado em detrimento da queima e outras destinações.

A tendência verificada nos dados do IBGE para 1991 e 2000 é observada também nas informações sanitárias do SNIS, segundo o qual, de 2001 a 2008, houve uma queda, ainda que pequena, na proporção da população fazendo uso

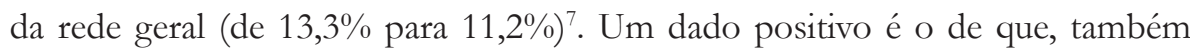

\footnotetext{
Possivelmente essa tendência se explique pelas reclamações documentadas no survey NEPO/ UNICAMP realizado naquela cidade, em 2010, a partir das quais ficou evidente a baixa qualidade do serviço público de abastecimento, executado pela Companhia de Saneamento do Pará (COSANPA), com o fornecimento de uma água turva, que gera receio na população acerca do seu uso, principalmente na preparação de alimentos. Assim, aqueles que dispõem
} 
segundo o SNIS, a cobertura da coleta de lixo no ano de 2008 em relação à população urbana já alcançava os 99,7\%.

Tabela 3: Proporção de moradores por tipo de abastecimento de água, instalação sanitária e destino de lixo, Altamira - 1991/2000.

\begin{tabular}{lrrr}
\hline Tipos & 1991 & 2000 \\
\hline Abastecimento de água & & \\
\hline Rede geral & 31,9 & \\
Poço ou nascente (na propriedade) & 51,1 & 74,9 \\
Outra forma & 17,0 & 5,4 \\
\hline Instalação sanitária & & \\
\hline Rede geral de esgoto ou pluvial & - & 1,8 \\
Fossa séptica & 31,5 & 29,2 \\
Fossa rudimendar & 48,7 & 54,9 \\
Vala & 3,3 & 3,1 \\
Rio, lago ou mar & - & 1,2 \\
Outro escoadouro & 0,1 & 1,6 \\
Não sabe o tipo de escoadouro & 0,0 & - \\
Não tem instalação sanitária & 16,3 & 8,1 \\
\hline Coleta de lixo & & \\
\hline Coletado & 44,2 & 73,0 \\
Queimado (na propriedade) & 22,3 & 16,2 \\
Enterrado (na propriedade) & 2,6 & 1,1 \\
Jogado & 27,0 & 9,4 \\
Outro destino & 4,0 & 0,4 \\
\hline
\end{tabular}

Fonte: IBGE - Censos Demográficos 1991 e 2000.

É importante ressaltar que, possivelmente, esse pequeno grupo da população com sistema de abastecimento de água por rede geral seja levado a estocar água no interior das suas residências com frequência, potencializando o número de criadouros para o mosquito Ae. aegypti. Isso ocorre porque, de acordo com dados coletados pelo survey NEPO/UNICAMP, a intermitência do serviço (falta d'água) é frequente para aqueles que dependem do sistema de abastecimento público por rede geral. Para os que possuem esse sistema (93 unidades domésticas das 500 presentes na amostra), 48,4\% têm abastecimento

de recursos suficientes efetuam a perfuração de poços nas suas propriedades para a obtenção de água de melhor qualidade. Todavia, vale apontar que a inexistência de um sistema de coleta de esgotos significa um grande risco para o abastecimento de água, pois os poços e fontes, principais formas de abastecimento da população, ficam altamente susceptíveis à contaminação. 
continuado (o dia todo, todos os dias). Os demais contam com o provimento de água apenas durante algumas horas, todos os dias (24,7\%), em dias alternados na semana $(23,7 \%)$ e menos de três dias por semana $(3,2 \%)$.

Destaca-se, ainda, que o abastecimento de água via poços domésticos também pode gerar potenciais criadouros do mosquito transmissor da dengue. Domicílios com poços podem encontrar nesses reservatórios profícuos criadouros do Ae. Aegypti. Além disso, as interrupções no sistema de fornecimento de energia elétrica (vivenciados ao longo de um mês de pesquisa de campo) são capazes de induzir a população ao acúmulo de água em recipientes domésticos improvisados, pois, sem eletricidade, a extração de água dos poços domésticos fica praticamente inviabilizada.

No que diz respeito à coleta de lixo, apesar de o sistema já abarcar quase a totalidade da população urbana, os resíduos sólidos continuam sendo uma questão de saúde pública a ser enfrentada, à medida que não se dispõe de aterro sanitário e o "lixão" municipal, localizado às margens da rodovia Transamazônica (BR-230), fica muito próximo à área urbana do município (Figura 6).

Figura 6: Lixão municipal próximo à área urbana de Altamira, PA.

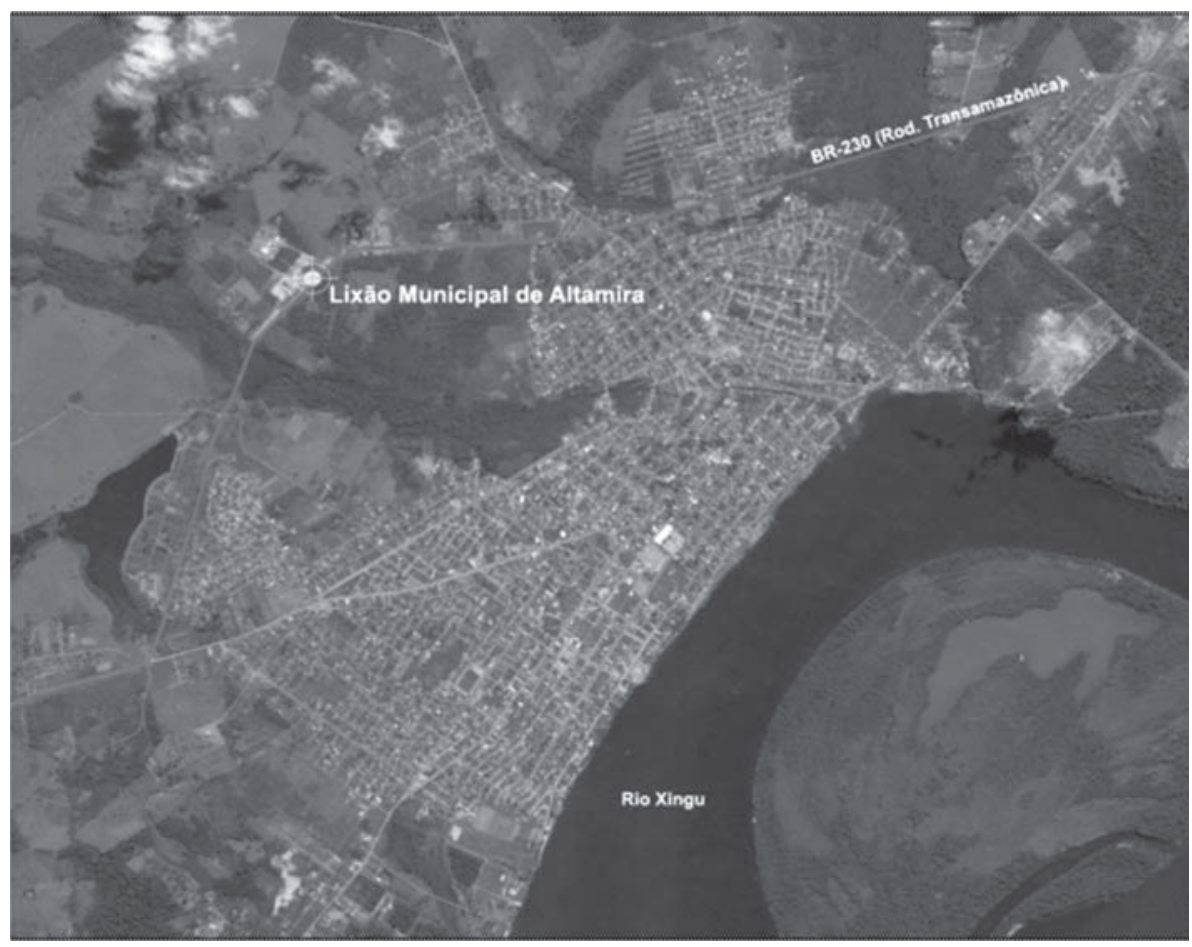

Fonte: Google Earth, 2011 (com modificações). 
Este fato gera preocupação porque o lixão propicia a existência, ao longo de todo o ano, de recipientes das mais variadas naturezas, que podem se tornar criadouros do mosquito Ae. aegypti. Com a existência de catadores que ali trabalham diariamente, apenas o aparecimento de um sorotipo de dengue circulante na região para o qual aquela população ainda não esteja imune, pode propiciar o desenvolvimento de uma epidemia, tendo em vista o trânsito contínuo desses trabalhadores entre o lixão e a cidade. Além disso, as condições sanitárias nas quais esses trabalhadores desempenham suas atividades, assim como a existência do lixão ao invés de um aterro sanitário, indicam a necessidade de ações do poder público também no sentido de sanar as problemáticas socioambientais decorrentes dessa realidade.

\subsection{AS EPIDEMIAS DE DENGUE NO MUNICÍPIO}

Uma epidemia é deflagrada quando uma doença específica ultrapassa os 300 casos por 100 mil habitantes. Como se verificou, Altamira possui população muito próxima a 100 mil habitantes (99.075, de acordo com o IBGE, 2010). Portanto, com 423 casos de dengue registrados pelo sistema público de saúde em 2009, tem-se patente a caracterização de uma epidemia no município. Esse cenário alarmante foi o motivador do presente estudo. Todavia, observase que a epidemia de dengue no município tornou-se ainda mais preocupante em 2010, quando os casos autóctones, isto é, aqueles cuja infecção ocorreu no próprio município, alcançaram o número de 1.361 (Figura 7). É importante destacar que casos de dengue estão distribuídos por todos os bairros de Altamira (PREFEITURA MUNICIPAL DE ALTAMIRA, 2011), não compondo uma exceção apenas de áreas periféricas ou socialmente mais "vulneráveis".

Figura 7: Casos autóctones de dengue, Altamira - 2001-2010.

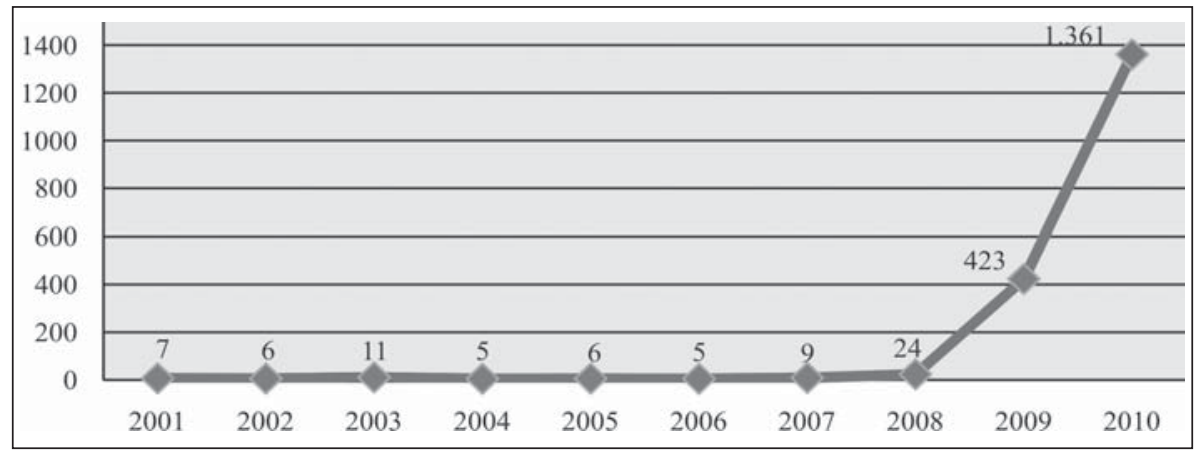

Fonte: Sistema Nacional de Agravos de Notificação (SINAN), 2011. 


\section{ANÁLISE E DISCUSSÃO DOS RESULTADOS}

Pôde-se verificar que a dengue consiste em um fenômeno complexo, por sua multicausalidade, ou seja, por possuir imbricações diversas e complexas entre seus fatores causais. Sendo assim, exige para seu controle políticas públicas intersetoriais, que abarquem, principalmente, as seguintes esferas: 1) Controle do mosquito vetor (vigilância epidemiológica ao longo de todo o ano); 2) Políticas urbanas de saneamento ambiental, em especial a ampliação e melhoria do serviço da coleta e destinação final dos resíduos sólidos e fornecimento de água de qualidade sem intermitências para toda população da área urbana; 3) Forte articulação das políticas de controle do mosquito vetor da dengue com a sociedade civil; 4) Realização de ações coordenadas entre as esferas municipal, estadual e federal; 5) Educação, informação e mobilização social; e 6) Pesquisa científica com vistas a fomentar a compreensão da dinâmica da doença, controle, diagnóstico e tratamento, além do desenvolvimento da vacina. É importante frisar que essas ações precisam ser realizadas em conjunto (Figura 8), com planejamento estratégico e recursos (financeiros, humanos e técnicos) adequados.

Figura 8: Intersetorialidade no controle da dengue.

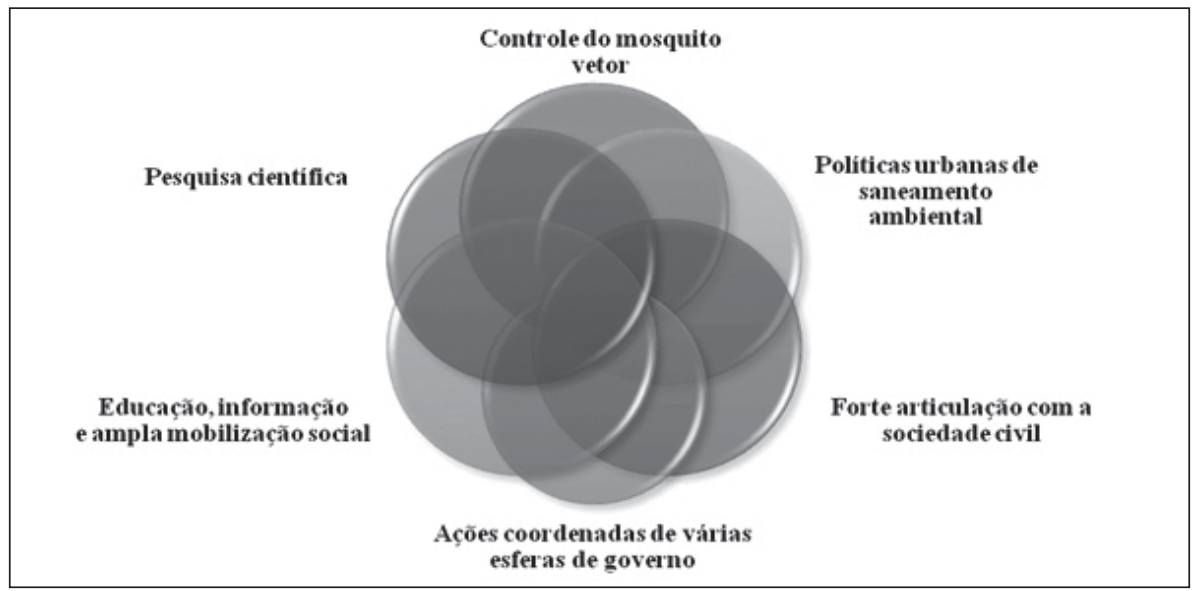

Fonte: Elaboração própria, com base em Gubler (1998).

A falta de conhecimento mais aprofundado da intimidade dos vírus da dengue ainda não permitiu a síntese da vacina. Entretanto, pesquisas vêm sendo realizadas nesse sentido, tendo em vista que uma das principais dificuldades é produzir uma vacina que imunize o indivíduo aos quatro sorotipos da doença (BEATTY et al., 2011; DONALISIO, 1999; LEE et al., 2011). De acordo com 
Costa (2011), mesmo diante das dificuldades para o desenvolvimento da vacina contra a dengue, já se cogita a possibilidade de que a população brasileira verá o sucesso no desenvolvimento dessa vacina antes de se ter superado o problema do saneamento básico no país. Cientistas esperam que a população possa ser imunizada contra os quatro sorotipos de dengue em cinco anos. Já no que diz respeito ao saneamento ambiental, o Governo Federal prevê que apenas em 2030 todos os brasileiros terão água encanada e rede coletora de esgotos em suas casas.

A pesquisa mais avançada para o desenvolvimento da vacina contra a dengue envolve o Núcleo de Doenças Infectocontagiosas da Universidade Federal do Espírito Santo, que auxilia nos testes clínicos de uma vacina desenvolvida pelo laboratório francês Sanofi Pasteur em 11 países tropicais. Além dessa pesquisa, o Instituto de Tecnologia em Imunobiológicos Bio-Manguinhos, ligado à Fundação Oswaldo Cruz (Fiocruz), no Rio de Janeiro; e o Instituto Butantan, vinculado à Secretaria de Estado da Saúde de São Paulo, trabalham na produção de vacinas, em parceria com laboratórios internacionais (COSTA, 2011).

Enquanto a vacina não se torna uma realidade no controle da dengue no Brasil, seguem as pesquisas buscando as mais eficazes formas de lidar com esse problema de saúde pública. Pelo motivo de a dengue compreender um fenômeno multifacetado, em decorrência da pluralidade de fatores envolvidos na deflagração de uma epidemia, sua investigação e as fontes de dados para seu estudo dependem do recorte temporal, espacial e temático-disciplinar do objeto. A investigação em profundidade pode ser realizada em cada um dos aspectos imbricados na multicausalidade da doença, para que se conheça sua dinâmica individual. Entretanto, como já citado, apenas a ação integrada sobre os diversos aspectos é que vai ser eficaz no controle da doença. Nesta pesquisa preconizou-se a perspectiva do saneamento básico (ou da sua falta) no agregado urbano de Altamira, analisando seu impacto na saúde da população através da epidemia de dengue. Observouse que na realidade estudada, diversos fatores estão correlacionados na situação epidêmica que eclodiu em 2009 e se intensificou em 2010.

Mas qual teria sido o "estopim" que culminou no quadro epidêmico de dengue na naquela cidade em 2009? A partir dos dados da Vigilância Epidemiológica de Altamira, é possível verificar que, acerca da densidade de infestação por mosquitos, o índice de infestação predial e o índice de Breteau ${ }^{8}$

8 O índice de infestação predial é a relação expressa em porcentagem entre o número de imóveis positivos (com Ae. aegypti) e o número de imóveis pesquisados. Assim, IP = (imóveis positivos/ imóveis pesquisados) x 100. Já o índice de Breteau é a relação entre o número de recipientes positivos e o número de imóveis pesquisados, corrigido de forma que o resultado seja expresso para 100 imóveis. Desse modo, IB = (recipientes positivos/imóveis pesquisados) $\times 100$ (BRASIL, 2005). 
subiram a níveis alarmantes de 2008 para 2009 (Figura 9). O Ministério da Saúde divide os índices de infestação predial dos municípios em estratos: 1) Inferiores a 1\%: condições satisfatórias; 2) De 1\% a 3,9\%: situação de alerta; 3) Superior a 4\%: há risco de surto de dengue (BRASIL, 2005). Assim, ao longo de 2009, o município de Altamira passou todos os meses em estado de alerta, com uma situação mais preocupante ao longo dos sete primeiros meses do ano, exatamente aqueles nos quais é maior a intensidade e a frequência das chuvas.

Figura 9: Índice de infestação predial, índice de Breteau e precipitação mensal, Altamira - 2008/2009.

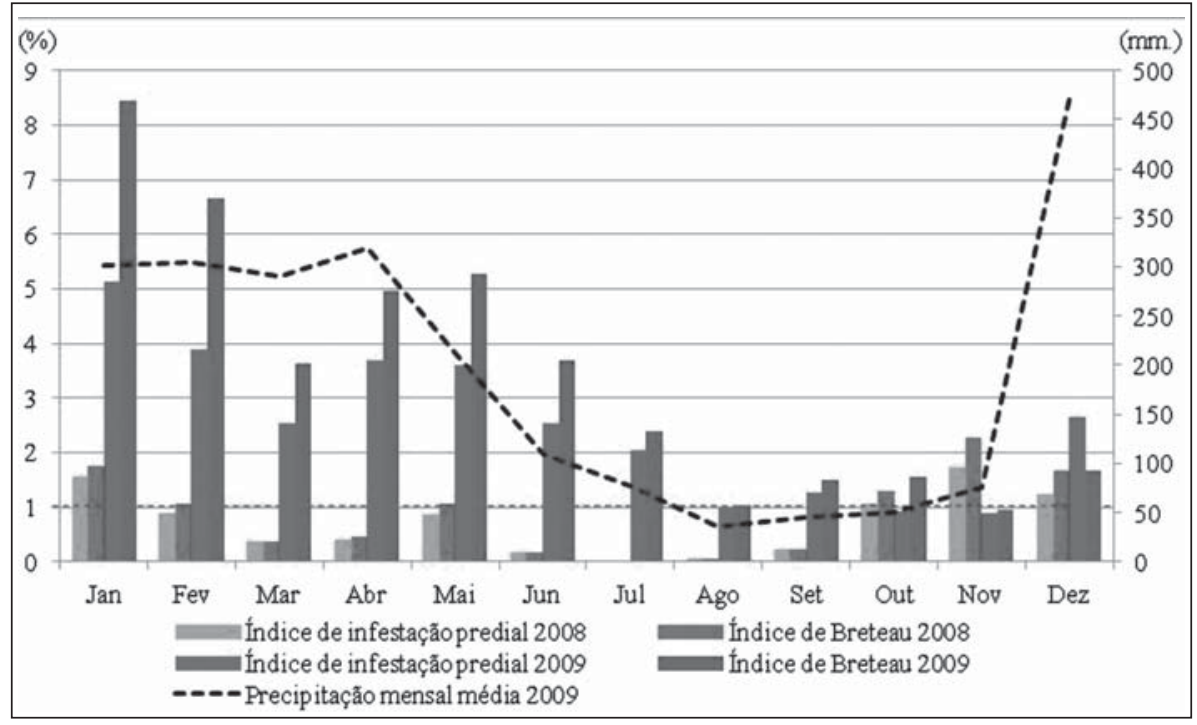

Fonte: Índices de infestação predial e de Breteau - Prefeitura Municipal de Altamira, 2011. Precipitação mensal média - Banco de Dados CP'TEC/ INPE.

Contudo, os altos índices de infestação pelo Ae. aegypti não são suficientes para explicar a epidemia de dengue em questão, pois não há casos da doença sem que se conte com a presença do vírus da dengue e pessoas susceptíveis a ele. Tem-se, então, o segundo fator imprescindível para o grande crescimento do número de casos de dengue em Altamira: a inserção na área urbana do município do sorotipo DEN-1, que já circulava nos municípios vizinhos (PREFEITURA MUNICIPAL DE ALTAMIRA, 2011). Tendo em vista que, apesar da circulação também do sorotipo DEN-2 - conforme constatam os exames laboratoriais realizados pelo Instituto Evandro Chagas (sediado em Belém, PA) -, na maioria dos casos de dengue diagnosticados nas epidemias de 2009 e 2010 está presente o sorotipo DEN-1, o que indica que aquela população ainda não estava imune a este sorotipo. 
Portanto, esses dois fatores (alto índice de infestação pelo mosquito vetor e inserção do sorotipo DEN-1), relacionados à condição de saneamento do município, marcada pela precariedade de abastecimento de água; o alto fluxo de circulação de pessoas, tendo em vista a importância regional do município; além da proximidade do lixão em relação à área urbana e os elevados índices pluviométricos combinados com altas temperaturas foram certamente alguns dentre os principais fatores que contribuíram para a deflagração da realidade epidêmica de dengue em Altamira no ano de 2009, ainda mais potencializada em 2010.

\section{CONCLUSÕES}

Procurou-se compreender, neste estudo, quais foram os principais fatores que contribuíram para a deflagração das epidemias de dengue no município de Altamira (PA) nos anos de 2009 e 2010. Para tanto, buscou-se realizar a análise da relação dialética estabelecida entre População e Ambiente.

A organização da vida humana interfere na extensão de uma epidemia no tempo, no espaço e sua distribuição na sociedade. Concluiu-se que, para compreender a complexidade da origem e da persistência no tempo de uma epidemia de dengue em um determinado espaço, faz-se necessário observar as especificidades do local em questão, naquilo que diz respeito às imbricações entre processos das dinâmicas da população e do ambiente, enquanto interligadas e interdependentes; e cuja análise precisa, necessariamente, ser realizada a partir de um ponto de vista multi/trans/interdisciplinar.

Neste trabalho, certamente seria pretensioso tentar abordar uma doença epidêmica tão complexa como a dengue na sua totalidade de expressão e relações. O saneamento básico, pensado a priori como componente quase inequívoco para compreender a eclosão da epidemia de dengue em Altamira nos anos de 2009 e 2010, mostrou ser não o único fator, mas provavelmente um dos mais importantes a serem considerados enquanto capazes de propiciar o desencadeamento de uma realidade epidêmica de dengue.

Este estudo permitiu concluir que o município em questão, em especial sua porção urbana, possui características socioambientais favoráveis à eclosão de epidemias de dengue. A inserção de um novo sorotipo pode ocorrer a qualquer momento, o que desencadeará uma nova epidemia. A chegada de considerável volume populacional de trabalhadores à cidade, em decorrência de um grande projeto de infraestrutura do Governo Federal, a Usina Hidrelétrica de Belo Monte, 
potencializa ainda mais o risco de entrada de novos sorotipos que, circulando em um curto espaço de tempo no mesmo local, proporcionará o aumento do risco de casos graves da doença. Portanto, para que não se deflagre uma epidemia de dengue anunciada, são necessárias ações pró-ativas que, além de mais eficazes e baratas, livram a população de um grande número de experiências dolorosas e traumáticas.

\section{REFERÊNCIAS}

ABRAHÃO, C. E. C. Dengue, abordagem ecossistêmica. In: AUGUSTO, L. G. da S.; CARNEIRO, R. M.; MARTINS, P. H. (Orgs.). Abordagem ecossistêmica em saúde - ensaios para o controle do dengue. Recife: Editora UFPE, 2005. p.137-145.

ABL- ACADEMIA BRASILEIRA DE LETRAS. Vocabulário Ortográfico da Língua Portuguesa. 5. ed. São Paulo: Global, 2009.

ALI, M.; WAGATSUMA, Y.; EMCH, M.; BREIMAN, R. F. Use of a geographic information system for defining spatial risk for dengue transmission in Bangladesh: role for Aedes albopictus in an urban outbreak. The American journal of tropical medicine and hygiene, v. 69, n. 6, p. 634-640. ASTMH. 2003. Disponível em: <http:/www.ajtmh.org/cgi/content/abstract/69/6/634>.

ANDRADE, J. S. C. de. Atlas da Dengue no Estado de São Paulo (19952005). Campinas: UNICAMP/ Instituto de Geociências, 2007.

ANDRADE, V. R. Distribuiçáo espacial do risco de dengue em regiáo do Município de Campinas. Tese (Doutorado) - Universidade Estadual de Campinas, Faculdade de Ciências Médicas, Campinas, 2009.

BARRETO, M. L.; TEIXEIRA, M. G.; BASTOS, F.I.; XIMENES, R. A. A., BARATA, R.B.; RODRIGUES, L. C. Sucessos e fracassos no controle de doenças infecciosas no Brasil: o contexto social e ambiental, políticas, intervençóes e necessidades de pesquisa. The Lancet. Terceiro de seis fascículos em Saúde no Brasil. p. 47-60. doi:10.1016/S0140-6736(11)60202-X, 2011. Disponível em: <http://www.thelancet.com/>.

BARRETO, M. L.; TEIXEIRA, M. G. Dengue no Brasil: situação epidemiológica e contribuições para uma agenda de pesquisa. Estudos Avançados, v. 22, n. 64, p. 53-72, 2008. doi: 10.1590/S0103-40142008000300005. 
BEATTY, Mark E.; BEUTELS, Philippe; MELTZER, Martin I.; et al. Health economics of dengue: a systematic literature review and expert panels assessment. The American journal of tropical medicine and hygiene, v. 84 , n. 3, p. 473488, 2011. doi: 10.4269/ajtmh.2011.10-0521.

BECKER, B. K. Síntese da produção científica em ciências humanas na Amazônia: 1990-2002. In: COSTA, W. M.da.; BECKER, B. K.; ALVES, D. S. (Orgs.). Dimensóes humanas da Biosfera-atmosfera na Amazônia. São Paulo: EDUSP, 2007. p. 13-38.

BENTHEM, B. H. B. Van; VANWAMBEKE, S. O.; KHANTIKUL, N. et al. Spatial patterns of and risk factors for seropositivity for dengue infection. The American Journal of Tropical Medicine and Hygiene, v. 72, n. 2, p. 201-208, 2005. Disponível em: <http://www.ncbi.nlm.nih.gov/pubmed/15741558>.

BRAGA, I. A.; VALLE, D. Aedes aegypti: histórico do controle no Brasil. In. Epidemiol. Serv. Saúde, v. 16, p. 113-118, 2007.

BRASIL. Ministério da Saúde. Cartilha dengue. 2011. Disponível em: <http:// portal.saude.gov.br/portal/arquivos/flash/cartilha_dengue.html>.

BRASIL. Ministério da Saúde. Fundação Nacional de Saúde (FUNASA). Programa Nacional de Controle da Dengue (PNCD). Brasília: Ministério da Saúde, 2002. 34p.

BRASIL. Ministério da Saúde. Secretaria de Vigilância em Saúde. Diretoria Técnica de Gestâo. Diagnóstico rápido nos municípios para vigilância entomológica do Aedes aegypti no Brasil - LIRAa: metogologia para avaliação dos índices de Breteau e Predial. Brasília: Ministério da Saúde, 2005.

BRASIL. Ministério da Saúde. Secretaria de Vigilância em Saúde. SINAN Sistema Nacional de Agravos de Notificação. Dengue 2001-2008 (Tabulação de dados). Disponível em: <http://dtr2004.saude.gov.br/sinanweb/>.

CÂMARA, F. P.; GOMES, A. F.; TEIXEIRA, G. T.dos et al. Clima e epidemias de dengue no Estado do Rio de Janeiro. Revista da Sociedade Brasileira de Medicina Tropical, v. 42, n. 2, p. 137-140, 2009.

CARMO, R. L. do. Urbanization, water and health in Brazil: Aspects of dengue fever epidemics. XXVI International Population Conference. IUSSP. Marrakech, 2009.

CORDEIRO, M. T.; SILVA, A. M.; BRITO, C. A. A. et al. Characterization of a dengue patient cohort in Recife, Brazil. The American Journal of Tropical 
Medicine and Hygiene, v. 77, n. 6, p. 1128-1134, 2007. Disponível em: <http:// www.ncbi.nlm.nih.gov/pubmed/18165535>.

COSTA, G. Brasileiros teráo vacina contra dengue antes de vencer problema de saneamento básico. Agência Brasil. 2011. Disponível em: <http://<www. agenciabrasil.ebc.com.br>.

COSTA-RIBEIRO, M. C. V. da; LOURENÇO-DE-OLIVEIRA, R.; FAILLOUX, A.-B. Low gene flow of Aedes aegypti between dengue-endemic and dengue-free areas in southeastern and southern Brazil. The American Journal of Tropical Medicine and Hygiene, v. 77, n. 2, p. 303-309, 2007. Disponível em: <http://www.ncbi.nlm.nih.gov/pubmed/17690403>.

CPTEC/ INPE-Centro de Previsão de Tempo e Estudos Climáticos/Instituto Nacional de Pesquisas Espaciais. Banco de dados. Disponível em: http://<http:// bancodedados.cptec.inpe.br/>.

DONALISIO, M. R. O dengue no espaço habitado. Sáo Paulo: Hucitec; Funcraft, 1999.

FARIA, V. Cinquenta anos de urbanização no Brasil. Novos Estudos CEBRAP, n. 29, p. 98-119, 1991.

FERREIRA, A. B. de H.. Aurélio século XXI: o dicionário da Língua Portuguesa. 3. ed. rev. e ampl. Rio de Janeiro: Nova Fronteira, 1999.

FERREIRA, I. T. R. N.; VERAS, M. A. de S. M.; SILVA, R. A. Participação da população no controle da dengue: uma análise da sensibilidade dos planos de saúde de municípios do Estado de Sáo Paulo. Cad. Saúde Pública, v. 25, n. 12, p. 2683-2694, 2009. doi: 10.1590/S0102-311X2009001200015.

GOOGLE EARTH. 2011. Software disponível para download em: <http:// www.google.com/intl/pt-PT/earth/index.html>.

GUBLER, D. J. Dengue and Dengue Hemorrhagic Fever. Public Health, v. 11, n. 3, p. 480-496, 1998.

HAYES, J.M.; GARCÍA-RIVERA, E.; FLORES-REYNA, R. et al. Risk factors for infection during a severe dengue outbreak in El Salvador in 2000. The American Journal of Tropical Medicine and Hygiene, v. 69, n. 6, p. 629-633. 2003. Disponível em: <http://www.ncbi.nlm.nih.gov/pubmed/14740880>.

HOGAN, D. J.; D’ANTONA, A. de O.; CARMO, R. L. do. Dinâmica Demográfica Recente da Amazônia. In: BATISTELA, M.; MORAN, E. F.; 
ALVES, D. S. (Orgs.). Amazônia: Natureza e Sociedade em Transformação. São Paulo: EDUSP, 2008. p. 71-116.

HOUAISS, A.; VILLAR, M. de S. Dicionário Houaiss da Língua Portuguesa. Rio de Janeiro: Objetiva, 2001.

IBGE-Instituto Brasileiro de Geografia e Estatística. Censos 1970, 1980, 1991, 2000 e 2010. Disponível em: <http://www.ibge.gov.br>.

LEE, B. Y.; CONNOR, D. L.; KITCHEN, S. B. et al. Economic value of dengue vaccine in Thailand. The American Journal of Tropical Medicine and Hygiene, v. 84, n. 5, p. 764-72, 2011. doi: 10.4269/ajtmh.2011.10-0624.

LEFÈVRE, F.; LEFÈVRE, A. M. C.; SCANDAR, S. A. S. et al. Representaçóes sociais sobre relaçóes entre vasos de plantas e o vetor da dengue. Rev. Saúde Pública, v. 38, n. 3, p. 405-414, 2004. Disponível em: <www.fsp.usp.br/rsp>.

LIMA, V. L.C.; CARMO, R. L. do; ANDRADE, V. R.; RESTITUTTI, M. C.; SILVEIRA, N. Y. J. da. Utilização de Sistema de Informação Geográfica na Rotina de Controle da Dengue. Boletim Epidemiológico Paulista, São Paulo, n. 3, p. 9-13, 2006.

LINHARES, E. K.; CELESTINO, A. de A. Consideraçôes sobre os casos registrados de dengue entre 2000 e 2005 e alguns fatores socioambientais na Zona Oeste do Rio de Janeiro. In: ENCONTRO NACIONAL DE ESTUDOS POPUlACIONAIS, 15. 2006, Caxambu. Anais... Caxambu: ABEP, 2006.

NATURE. Editorial. Dengue fever climbs the social ladder. Nature, v. 448, n. 7155, p. 734-735, 2007. doi: 10.1038/448734a.

OMS-ORGANIZAÇÃO MUNDIAL DA SAÚDE. Dengue guidelines for diagnosis, treatment, prevention and control, 2009. Disponível em: <http:// whqlibdoc.who.int/publications/2009/9789241547871_eng.pdf>.

OMS-ORGANIZAÇÃO MUNDIAL DA SAÚDE. Report of the Scientific Working Group meeting on Dengue. Genebra: Special Programme for Research \& Training in Tropical Diseases (TDR), 2006. 1-5 out.

ORGANIZACIÓN PANAMERICANA DE LA SALUD. Marco de Referencia para la Nueva Generación de Programas de Prevención y Control del Dengue em las Américas. Washington: OMS, 2001.

PREFEITURA MUNICIPAL DE ALTAMIRA, Plano Diretor Municipal, 2003. 
PREFEITURA MUNICIPAL DE ALTAMIRA. Secretaria de Saúde. Vigilância Epidemiológica. Informativo Epidemiológico da Dengue, n. 1, abr. 2011.

UNICAMP-PREFEITURA UNIVERSITÁRIA. Aedes a $\boldsymbol{e} \boldsymbol{y} \boldsymbol{y} \boldsymbol{p} \boldsymbol{t} \boldsymbol{i}$ : quem ele é? Disponível em: <http://www.prefeitura.unicamp.br/prefeitura/ca/ DENGUE/3dengue_unicamp.html>.

RANGEL-S, M. L. Dengue: educação, comunicação e mobilização na perspectiva do controle - propostas inovadoras. Interface, Botucatu, v. 12, n. 25, p. 433-441, 2008.

RIBEIRO, M. A. C. Amazônia Legal: rede e fluxos na nova divisão territorial do trabalho. IN: SIMPÓSIO DE GEOGRAFIA URBANA, 3. 1993. Rio de Janeiro. Anais... Rio de Janeiro, 1993. p. 177, 178.

RIPSA-Rede Interagencial de Informaçóes para a Saúde. Taxa de incidência de dengue - ficha de qualificação. Indicadores de morbidade e fatores de risco, 2011. Disponível em: <http://tabnet.datasus.gov.br/>.

SANTOS, S. L. dos; AUGUSTO, L. G. da S. Modelos de controle de dengue, pontos e contrapontos. In: AUGUSTO, L. G. da S.; CARNEIRO, R. M.; MARTINS, P. H. (Orgs.). Abordagem ecossistêmica em saúde - ensaios para o controle do dengue. Recife: Editora UFPE, 2005. p. 115-136.

SHEPARD, D. S.; COUDEVILLE, L.; HALASA, Y. A. et al. Economic impact of dengue illness in the Americas. The American Journal of Tropical Medicine and Hygiene, v. 84, n. 2, p. 200-207, 2011. doi: 10.4269/ajtmh.2011.10-0503. SIQUEIRA, J. B.; MARTELLI, C. M. T.; MACIEL, I. J. et al. Household survey of dengue infection in central Brazil: spatial point pattern analysis and risk factors assessment. The American Journal of Tropical Medicine and Hygiene, v. 71, n. 5, p. 646-651, 2004. Disponível em: <http:/www.ncbi.nlm.nih.gov/ pubmed/15569799>.

SNIS-Sistema Nacional de Informações sobre Saneamento. Aplicativo Série Histórica 9. Brasília: Ministério das Cidades/Secretaria Nacional de Saneamento Ambiental, 2011. Disponível em: <http://www.snis.gov.br>.

TAUIL, P. L. Urbanização e ecologia do dengue. Cad. Saúde Pública, v. 17, p. 99-102, 2001.

THE ROCKEFELLER FOUNDATION. Health Sciences Division. Dengue Control: The Challenge to the Social Sciences. Baltimore: The Johns Hopkins University School of Hygiene and Public Health, 1988. Relatório de Workshop. 